\title{
Experimental analysis of fluid-filled aluminium tubes subjected to high-velocity impact
}

\author{
D. Varas, J. López-Puente, R. Zaera* \\ Department of Continuum Mechanics and Structural Analysis, University Carlos III of Madrid, Avda. de la Universidad 30, 28911 Leganés, Madrid, Spain
}

\begin{abstract}
A B S T R A C T
Hydrodynamic ram (HRAM) is a phenomenon that occurs when a high energy object penetrates a fluid filled container. The projectile transfers its momentum and kinetic energy through the fluid to the surrounding structure increasing the risk of catastrophic failure and excessive structural damage. It is of particular concern in the design of wing fuel tanks for aircraft since it has been identified as one of the important factors in aircraft vulnerability. For the present work, water filled aluminium square tubes (6063 T5) were subjected to impact by steel spherical projectiles ( $12.5 \mathrm{~mm}$ diameter) at impact velocities of $600900 \mathrm{~m} / \mathrm{s}$. The aluminium tubes were filled at different volumes to study how an air layer inside the tank might influence the impact behaviour. The test boxes were instrumented with five strain gauges and two pressure transducers. The formation process of the cavity was recorded with a high speed camera. This work presents the results of these tests.
\end{abstract}

\section{Introduction}

The process by which a high speed projectile penetrates a fluid filled tank and transfers kinetic energy to the surrounding walls is known as hydrodynamic ram (HRAM). The HRAM effect in fuel tanks is identified as one of the important factors in aircraft vul nerability, since the fuel tanks represent the largest exposed area of all the vulnerable components. The Vietnam War, in which low flying aircrafts were downed by small arms and automatic fire, demonstrated the importance of this phenomenon. More recently, in the war "Desert Storm", some $75 \%$ of all aircraft losses were re lated with the fuel system [1]. These losses were due primarily to three main causes: fire, explosion, and HRAM. Statistics indicate that HRAM is by far the most lethal of these three [2]. HRAM is especially dangerous for aircraft with extremely lightweight de signs. They commonly use wing integral fuel tanks, and the re sistance of their structure cannot be improved by strengthening the airframe, since this would go counter to the requirements of a lightweight design.

Vulnerability to HRAM is usually but not exclusively related to military aircraft. In 1990 the Federal Aviation Administration (FAA) established the Aircraft Catastrophic Failure Prevention Research Program, in which one research area was the analysis of the effects of an uncontained turbine engine fragment penetration in aircraft

\footnotetext{
* Corresponding author. Tel.: +34 916249 983; fax: +34 916249430 .

E-mail address: ramon.zaera@uc3m.es (R. Zaera).
}

fuel tanks [3]. In 2000, when a Concorde crashed after takeoff from Charles de Gaulle airport (France), the final investigation report revealed that the HRAM had played a significant role in the aircraft failure.

Hydrodynamic ram consists of four principal stages: shock, drag, cavitation and exit (Fig. 1). Each stage contributes to structural damage in a different way and to a different extent. When the projectile penetrates the wall of the fluid filled structure, the im pact energy is transferred to the fluid generating a high pressure hemispherical shock wave. This leads to damage primarily in the vicinity of the impact position. During the drag phase, the projectile travels through the fluid, while its kinetic energy is partially transformed into fluid motion as the projectile is slowed by viscous drag. The displacement of the fluid from the projectile path gen erates a radial pressure field. In contrast to the pressure field that develops during the shock phase, the fluid is accelerated gradually instead of impulsively. This causes less intense peak pressures but of greater temporal extent. The displacement of fluid during the drag stage forms a cavity behind the projectile. The subsequent expansion and collapse (oscillations) of the cavity is known as the cavitation stage. The oscillations of the cavity can cause significant pressure pulses. The final stage occurs when the projectile exits the container. In contrast to the perforation of the front wall, the exit of the projectile occurs through a pre stressed wall, caused by the initial shock stage and the subsequent loading by the fluid.

For a better understanding of HRAM and the associated fluid structure interaction, various groups within the US Defence Department in the 70 s expended considerable research effort. 


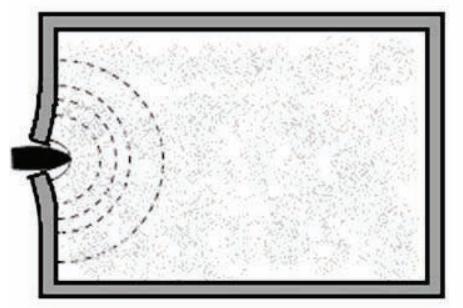

SHOCK

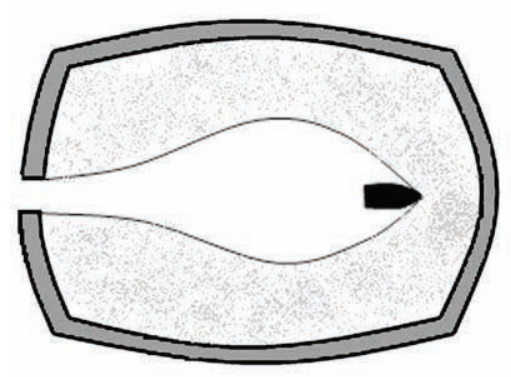

CAVITATION

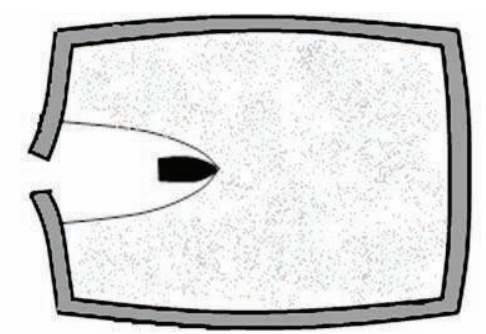

DRAG

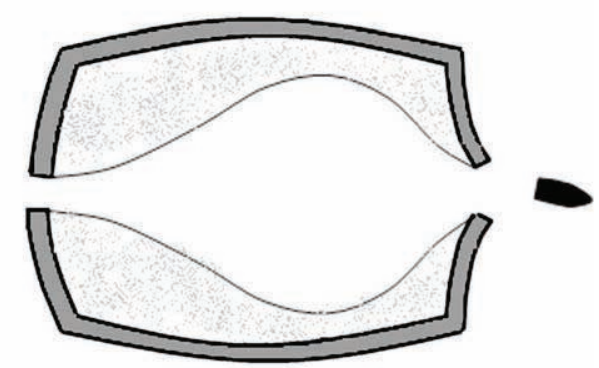

EXIT

Fig. 1. Phases of hydrodynamic ram.

The Naval Weapons Center (NWC), China Lake, California, con ducted a hydrodynamic ram project in which a series of ballistic tests were performed and fluid pressure was measured at several locations for a variety of projectiles. The results of these tests as well as their analyses are reported in Ref. [4]. A digital computer code for predicting the drag phase fluid pressure in a rectangular tank due to ballistic penetrators, based upon the theory of Lund strom [5] and the empirical data of Ref. [4], was subsequently de veloped by Lundstrom and Fung [6]. The second phase of the same project involved the characterization of the fluid structure in teraction during the loading of the fuel tank walls by the HRAM pressure. In support of this goal, the strains at several locations were measured. The description of the tests made and a selection of the results are reported in Ref. [7]. At the same time, the Naval Postgraduate School (NPS) conducted an analytical and experi mental hydrodynamic ram program in conjunction with the NWC project. Fluid pressures and entry wall strains were measured for several projectile sizes and energy levels. The tests and their results are reported in Refs. [8 18]. The crack damage in fuel tank walls was also studied with the aforementioned tests [19] and a method for predicting the amount of cracking was presented. The Univer sity of Dayton Research Institute also performed several impact experiments on fuel tanks during the 70s. Bless et al. [20] carried out experiments with spherical projectiles of 11.1 and $14.3 \mathrm{~mm}$ diameter in the velocity range $1.52 .4 \mathrm{~km} / \mathrm{s}$, compiling data for entrance and side panel displacement, fluid pressure, and the projectile trajectory. Some of the conclusions reached were that 2024 T3 aluminium alloy is far more resistant to ram damage than 7075 T6 aluminium alloy and that ballistic foam or styrofoam are extremely effective in defeating entrance panel but are of marginal utility in defeating ram effects at exit panels. Another work of Bless [21] presents the failure, displacement, and pressure data for alu minium and graphite epoxy panels impacted by spheres and cubes of different weights. The failures were invariably catastrophic, and failure thresholds were abrupt. When cracks formed, they ran across the panels except when stiffeners were present, and thus it was concluded that stiffeners and foam suppressed catastrophic crack formation. Bless also found that the dependence of failure on impact parameters could be approximately represented as
$V^{2} D / W$ constant, where $V$ is projectile velocity, $D$ is projectile diameter, and $W$ is panel thickness. In all the above mentioned works the fluid filled container consists of a structure where dif ferent panels can be placed and the top of the tank is always open. In 1983 Copland [22] evaluated the ability of different inerting agents to attenuate HRAM in armoured vehicles. Two different containers were impacted by $12.7 \mathrm{~mm}$ AP bullets and $11.9 \mathrm{~mm}$ steel spheres. The results indicate that the destructive effects of HRAM may be enhanced by the addition of the inerting agent called "Explosafe" to liquid containing cells, while the addition of foam may have attenuated the effects of HRAM. The Advisory Group for Aerospace Research and Development conducted impact tests in 1988 to study the influence of projectile shapes, fluids, and impact angles on aluminium and carbon epoxy tanks [23]. Some of their conclusions were that the shape of the fragment may have a sub stantial effect on the HRAM structural response of a fuel tank and that stitching of stiffeners to the panels provides transverse re inforcement as well as resistance to the propagation of de lamination damage. They also observed that the severe structural damage of graphite/epoxy exit panels was concentrated in the vi cinity of the fragment perforation sites, whereas the severe damage of the entry panels was in the vicinity of both the panel joints and the fragment perforation sites. In 1989 Lundstrom and Anderson [24] conducted an experiment where 23 and $30 \mathrm{~mm}$ high explosive incendiary (HEI) rounds were shot into a rectangular thick steel tank that was filled with water and open on the top. Fluid pressure data at several points were reported. Sparks et al. [25] carried out an experiment to examine the HRAM loads generated by a $12.7 \mathrm{~mm}$ projectile entering a water filled container. The container was similar to the one described in previous works. Pressure data at different points were measured and the projectile trajectory recorded with two high speed digital cameras. Those data were compared with the results of two different simulation techniques which demonstrate a significant potential to capture the initial physics of the HRAM event. In 2004 Seddon et al. [26] performed tests in which nylon projectiles weighting $2.5 \mathrm{~kg}$ were launched at velocities from 14 to $21 \mathrm{~m} / \mathrm{s}$ against a steel fuel tank filled at dif ferent volumes. They compared numerical and experimental re sults of the acceleration of the fuel tank front wall showing a good 
correlation. Poehlmann Martins et al. [27] compared their experi mental results with the numerical ones, showing good agreement also. In this case, the test consisted of a $25.4 \mathrm{~mm}$ steel ball travelling along the centreline of a cylindrical aluminium container with open ends and filled with water. Pressure data were taken all along the projectile trajectory, but no attention was paid to the fluid struc ture interaction due to the high strength and stiffness of the con tainer. In the work of Nishida and Tanaka [28], thin walled aluminium alloy tubes of $50 \mathrm{~mm}$ diameter were impacted by spherical steel projectiles of different diameters at impact velocities ranging from 40 to $200 \mathrm{~m} / \mathrm{s}$. Among other conclusions, they found that filling the tubes with water decreased wall strength, and that the crack and the perforation limit velocities depended on the ul timate strength and strain of the material, in addition to the di ameter of the projectile. It is worth mentioning other kinds of tests performed to study the fluid structure interaction [29]: a fluid filled tank was impacted with the ground, showing accelerations and forces at different points of the tank.

Since most of the works mentioned concern on velocities higher than $900 \mathrm{~m} / \mathrm{s}$ or lower than $200 \mathrm{~m} / \mathrm{s}$, there is a large gap that ex cludes velocities of practical interest. Furthermore, almost all the above experimental works employed open containers with a steel structure, and their behaviour could be completely different from that of a closed tank, as in the case of a fuel tank. Lastly, the in fluence of different fluid volumes on the behaviour of a closed container has not been studied in depth in order to assess its importance.

In the present work, experiments are performed on water filled aluminium square tubes (6063 T5) subjected to impact by steel spherical projectiles $(12.5 \mathrm{~mm}$ diameter) at impact velocities of $600900 \mathrm{~m} / \mathrm{s}$. The aluminium tubes were filled at different volumes with the aim of studying the way in which an air layer inside the tank influences the impact behaviour. The test boxes were instru mented with five strain gauges and two pressure transducers. The process of formation of the cavity was recorded with a high speed camera. This work presents the results and analyses of these tests.

\section{Experimental setup}

The sketch of the experimental device used for impact tests is shown in Fig. 2.

\subsection{Characteristics of the specimen. Assembly and instrumentation}

The test boxes consisted of $6063 \mathrm{~T} 5$ square aluminium tubes $150 \mathrm{~mm}$ wide, $2.5 \mathrm{~mm}$ thick, and $750 \mathrm{~mm}$ long. The specimens were closed with two PMMA windows $30 \mathrm{~mm}$ thick, fixed to the specimen with four steel bars; these transparent panels allow the recording of the impact process. A similar setup was proposed by Nishida and Tanaka [28]. The contact points between PMMA win dows and specimen were sealed with silicone in order to avoid fluid leakage [25] (Fig. 3).

The aluminium boxes were instrumented with two pressure transducers and five strain gauges. The pressure pulse was recorded with a PCB 138A06 sensor [25] having a measurement range of 34.4 MPa and a resolution of $0.07 \mathrm{kPa}$. Two holes were made on the lower wall of the specimen to place both sensors inside the water. Their position is shown in Fig. 4. The strain pulses were measured with uniaxial gauges ( $350 \Omega, 2.120$ Gage factor) from Vishay Mea surements Group Inc. Two gauges were located in the entry wall, another two in the exit wall at the same position as the entry ones, and a last one in the lower wall, as is shown in Fig. 4.

A Dewetron DEWE 800 data acquisition device was used to re cord all the signals. This system can record at a sampling rate of $1 \mu \mathrm{s}$ and synchronise the data with the video recording. The tubes were filled with water at different volume fractions: 60,75 , and $100 \%$.

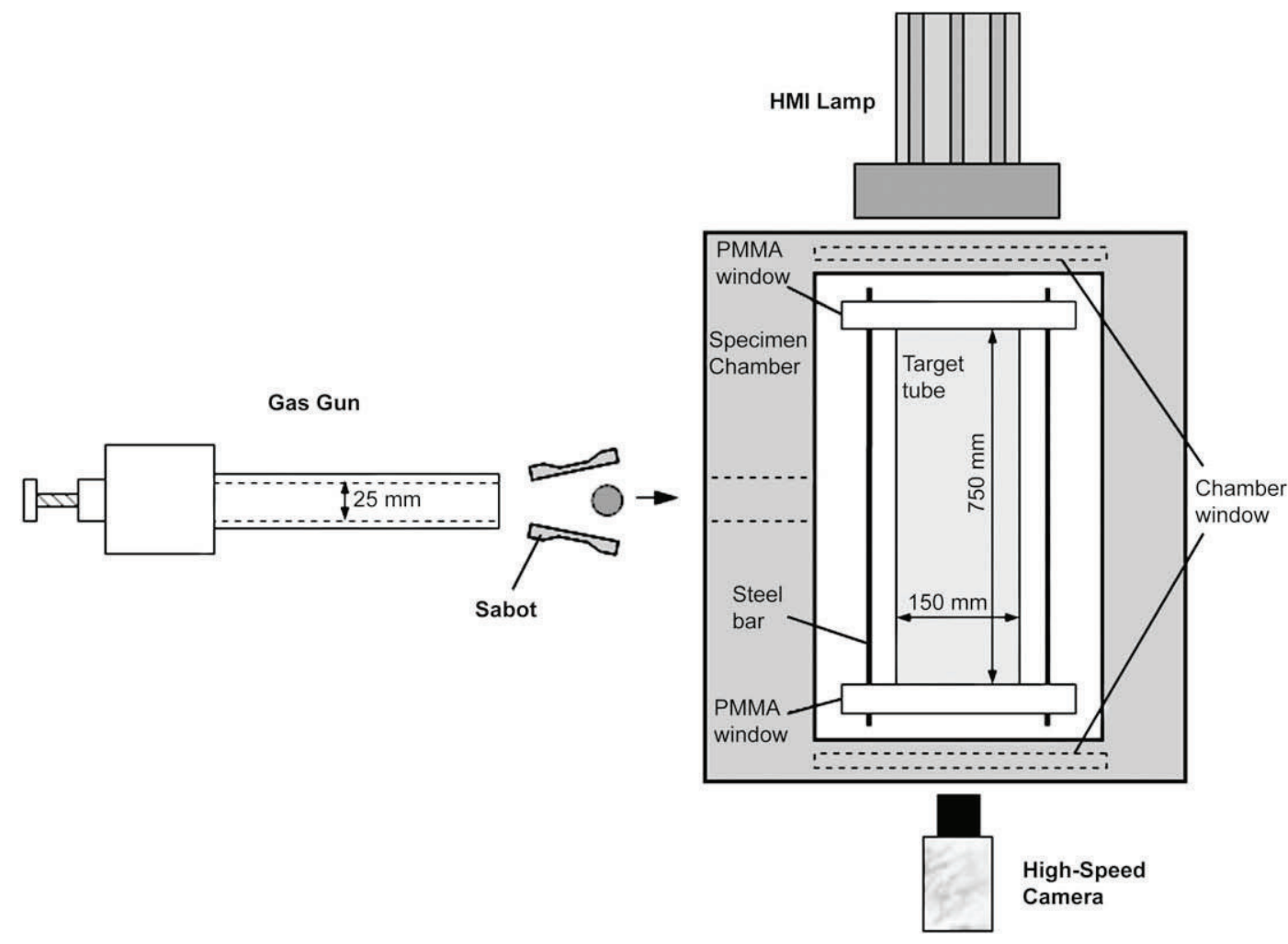

Fig. 2. Sketch of the experimental device used for impact tests. 


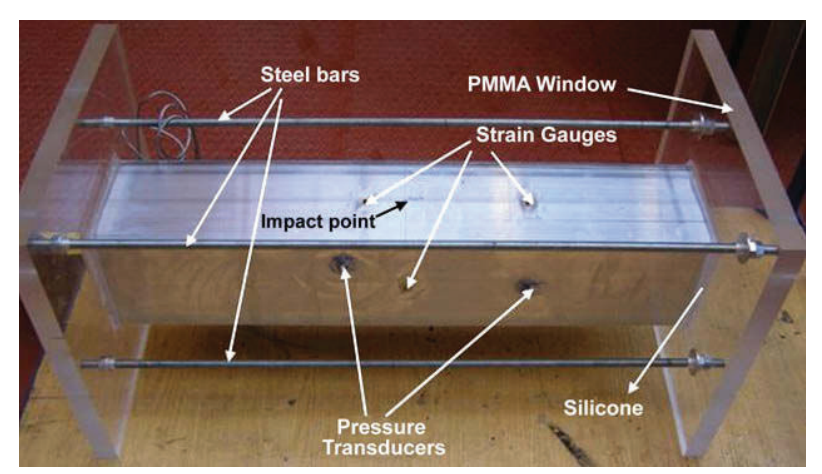

Fig. 3. Test box closed.

\subsection{Gas gun and specimen chamber}

A one stage light gas gun with a 4.71 chamber which stores gas at a maximum pressure of 300 bar was used with helium. The length of the barrel was $4.5 \mathrm{~m}$ and its calibre $25 \mathrm{~mm}$. The gun was aimed at an armoured steel specimen chamber box $1 \times 1 \times 1 \mathrm{~m}^{3}$ where the specimen was placed during the impact test. The dis tance between this chamber and the tip of the barrel was $3.0 \mathrm{~m}$. The chamber had a small circular window in the front and two large lateral windows to illuminate the specimen and capture the video sequence of the impact, Fig. 2.

\subsection{Projectile}

The projectile to be launched against the box was a steel sphere with a diameter of $12.5 \mathrm{~mm}$ and a mass of $8 \mathrm{~g}$. Different sabots were tested to launch the projectile in order to ensure that their valves opened before reaching the target chamber. Finally, a PVC sabot with two valves weighing $21 \mathrm{~g}$ was used at two impact velocities: 600 and $900 \mathrm{~m} / \mathrm{s}$.

\subsection{High speed camera and lighting system}

To record the sequence of the projectile penetrating the fluid and the development of the cavity, a Photron Ultima APX RS digital high speed camera was employed. The selected frame rate was 36,000 per second, so that a frame is taken every $27.7 \mu \mathrm{s}$. The resolution was $384 \times 160$ pixels and the shutter was set to $1 \mu \mathrm{s}$. These settings were selected based on early testing and represent an optimal tradeoff between available lighting and the minimization of blur in the im ages. Lighting was provided by an Arrisun 12 Plus lamphead with a 1200 W Hydrargyrum Medium arc Iodide (HMI) lamp.

\section{Experimental results}

\subsection{Video sequences}

Several sequences recorded by the high speed camera are shown below. Figs. 58 show how the projectile penetrates the fluid, cre ating a cavity behind it as it travels through the fluid. Since pene tration of the projectile in the fluid is subsonic, spherical wave fronts propagating in the same direction of the projectile as well as their rarefactions with the test box can be detected in the pictures. In the complete video, several collapses and expansions (oscillations) of the cavity are appreciated during several microseconds. In partially filled cases it can be seen how the cavity raises the free surface of the fluid and a layer of fluid accelerates upwards. This layer will impact at high velocity the upper wall of the box. Figs. 6 and 7 reveal the rarefaction wave, formed at the free surface of the fluid, following the initial wave. As a result, the pressure drops drastically in the fluid and some bubbles appear close to the free surface. A similar effect was found $[30,31]$ in the free surface of a liquid submitted to un derwater explosion. These bubbles collapse when the pressure in the fluid increases again due to the advance of the cavity.

Fig. 9 shows the deformation process of one tube completely filled when it is impacted at $900 \mathrm{~m} / \mathrm{s}$. The frame rate was 30,000 frames per second. The resolution was $256 \times 256$ pixels and the shutter was set to $2 \mu \mathrm{s}$. As can be observed, most of the deformation of the tube takes place after the projectile exits, when the cavity reaches its largest size. The maximum displacement of the walls occurs around $1.5 \mathrm{~ms}$, and then a slight elastic recovery is visible later in the last two images.

\subsection{Time history of the projectile trajectory}

By means of the digital high speed camera, it is possible to determine the velocity and the position of the projectile inside the fluid. These experimental data are compared with analytical results (Fig. 10), obtained from Newton's second law,

$$
m_{\mathrm{p}} \frac{\mathrm{d} V_{\mathrm{p}}}{\mathrm{d} t} \quad \frac{1}{2} \rho_{\mathrm{w}} A_{0} C_{\mathrm{d}} V_{\mathrm{p}}^{2}
$$

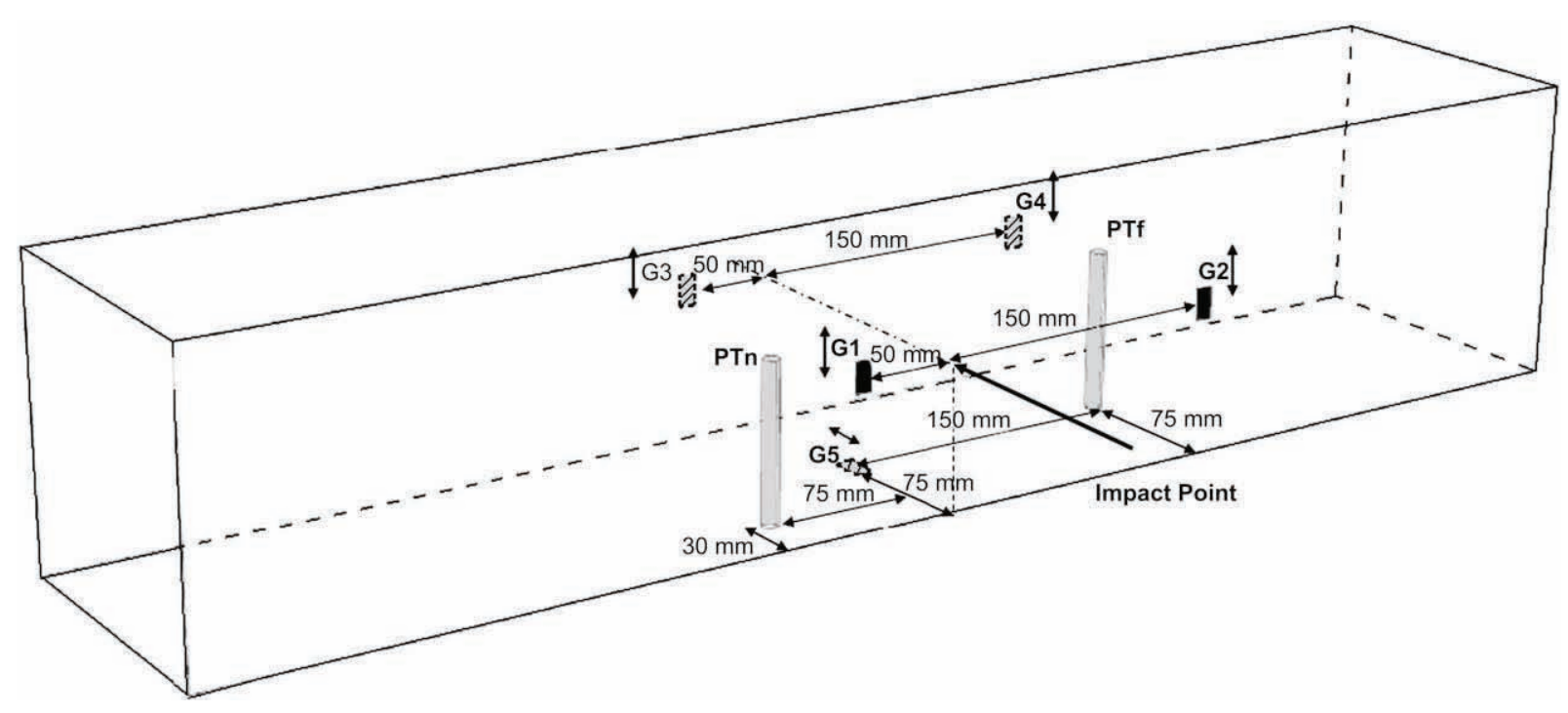

Fig. 4. Sketch of the test box instrumented. 


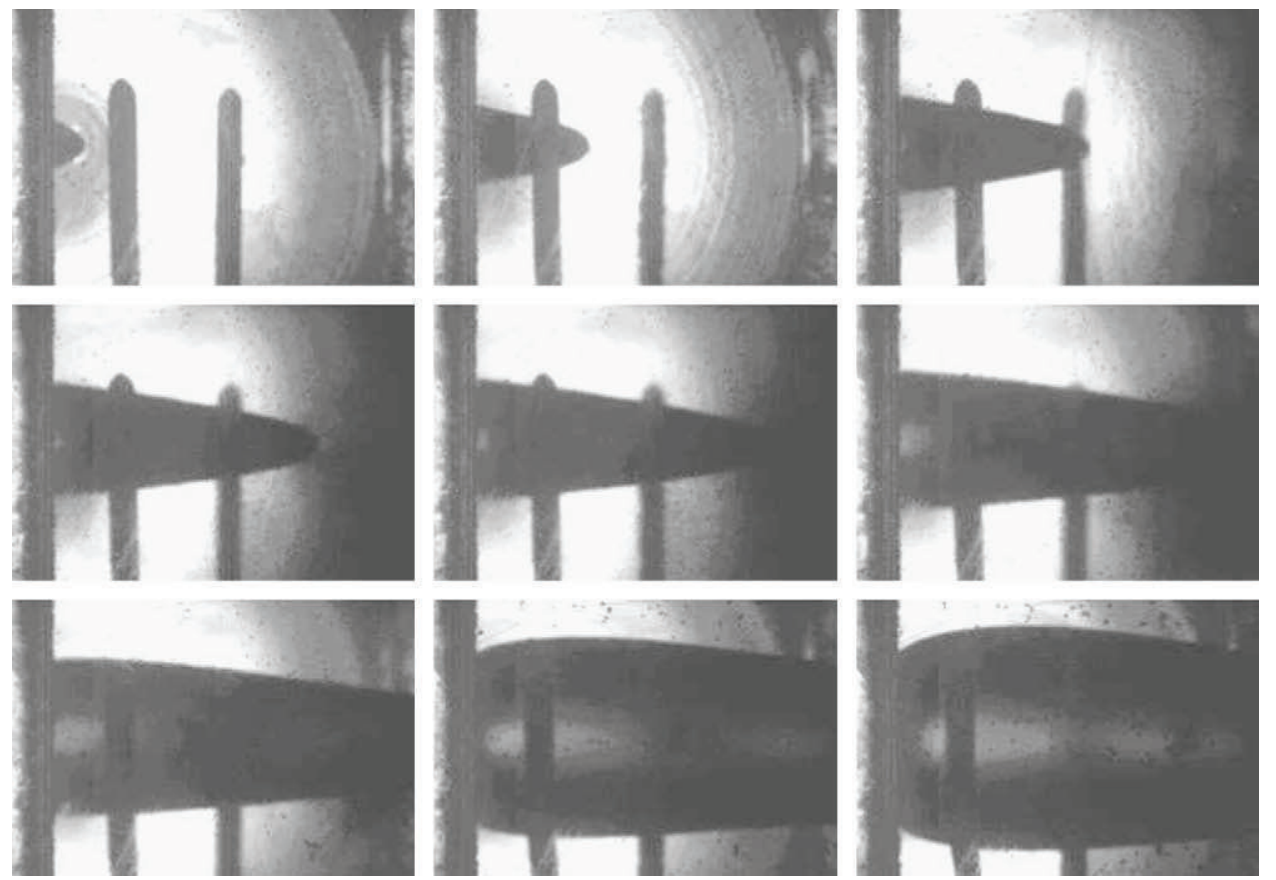

Fig. 5. Sequence of projectile penetration into tube filled $100 \% . V \quad 600 \mathrm{~m} / \mathrm{s}$; images taken at $29 \mu \mathrm{s}, 84.4 \mu \mathrm{s}, 139.8 \mu \mathrm{s}, 195.2 \mu \mathrm{s}, 222.9 \mu \mathrm{s}, 306 \mu \mathrm{s}, 416.8 \mu \mathrm{s}, 721.5 \mu \mathrm{s}$, and $943.1 \mu \mathrm{s} ; t \quad 0$ corresponds to initial contact.

where $m_{\mathrm{p}}$ and $V_{\mathrm{p}}$ denote the bullet mass and velocity, $\rho_{\mathrm{w}}$ is the fluid density, $A_{0}$ is the projected frontal area of the projectile and $C_{\mathrm{d}}$ is a dimensionless drag coefficient. According to the range of veloci ties considered, a value of 0.4 for $C_{d}$ was chosen [32]. Noting that

$V_{\mathrm{p}} \quad \frac{\mathrm{d} x_{\mathrm{p}}}{\mathrm{d} t}$

where $x_{\mathrm{p}}$ is the position of the projectile along the trajectory, Eq. (1) is transformed to $\frac{\mathrm{d} V_{\mathrm{p}}}{\mathrm{d} x_{\mathrm{p}}} \quad \beta V_{\mathrm{p}}$

the velocity decay coefficient $\beta$ is defined as

$$
\beta \quad \frac{1}{2 m_{\mathrm{p}}} \rho_{\mathrm{w}} C_{\mathrm{d}} A_{0}
$$

The position data are well known by means of the video, so that the values agree well with analytical curves. The velocity values
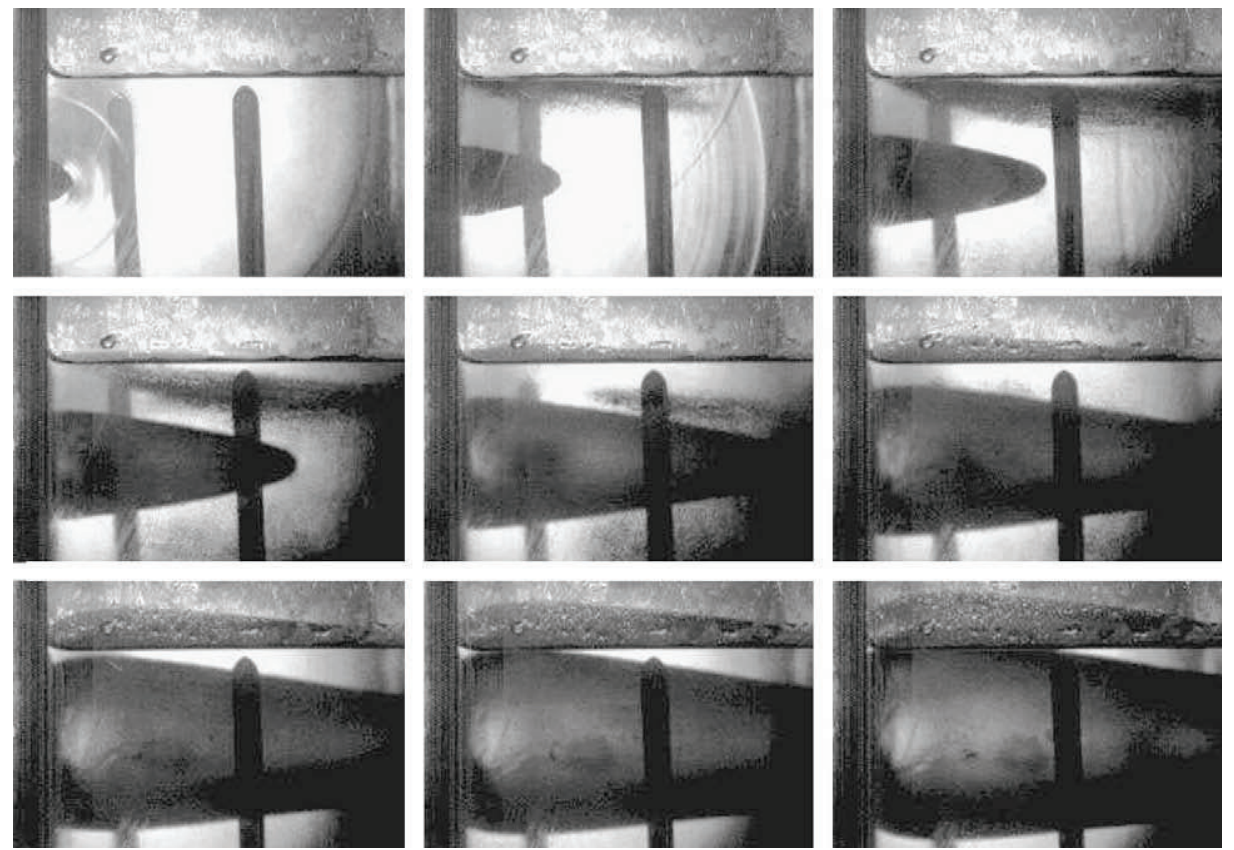

Fig. 6. Sequence of projectile penetration into tube filled $75 \% . V \quad 600 \mathrm{~m} / \mathrm{s}$; images taken at $18 \mu \mathrm{s}, 73.4 \mu \mathrm{s}, 128.8 \mu \mathrm{s}, 184.2 \mu \mathrm{s}, 267.3 \mu \mathrm{s}, 350.4 \mu \mathrm{s}, 461.2 \mu \mathrm{s}, 516.6 \mu \mathrm{s}$, and $599.7 \mu \mathrm{s} ; t \quad 0$ corresponds to initial contact. 

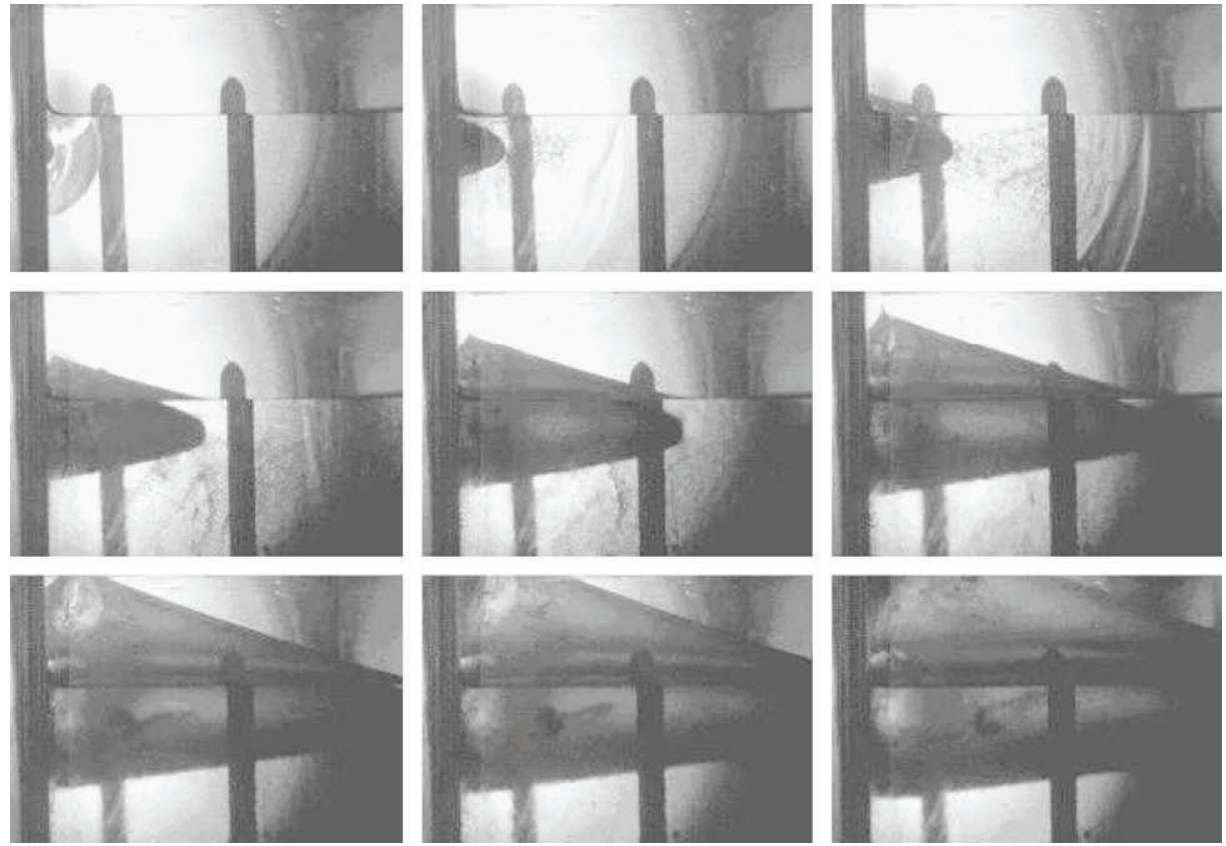

Fig. 7. Sequence of projectile penetration into tube filled $60 \% . V \quad 600 \mathrm{~m} / \mathrm{s}$; images taken at $15 \mu \mathrm{s}, 42.7 \mu \mathrm{s}, 70.4 \mu \mathrm{s}, 125.8 \mu \mathrm{s}, 181.2 \mu \mathrm{s}, 236.6 \mu \mathrm{s}, 319.7 \mu \mathrm{s}, 375.1 \mu \mathrm{s}$, and $458.2 \mu \mathrm{s} ; t \quad 0$ corresponds to initial contact.

determined with the camera do not correspond exactly with the velocity at each point, since they are calculated as an average be tween two frames. Therefore there are some differences with an alytical data. Nevertheless, same trend is noted.

As a result of the decay in the velocity of the projectile, its kinetic energy is progressively converted into pressure and kinetic energy in the fluid and later into plastic deformation of the tube.

\subsection{Pressure time history}

As mentioned above, two pressure gauges were used to record the time history of the HRAM pressure wave as it propagated through the fluid. One of the pressure gauges (PTn) was located near the impact point, at $30 \mathrm{~mm}$ from the wall, and $75 \mathrm{~mm}$ from the shot line (Fig. 4), while the other (PTf) was in the middle of the tube, at $150 \mathrm{~mm}$ from the projectile trajectory (Fig. 4). The pressure time histories depicted in Fig. 11 represent the typical curves found for pressure measurements at PTn and PTf at different velocities and volume percentages. It can be seen that the pressure in PTn starts to increase at about $60 \mu \mathrm{s}$ after the impact, while PTf starts to measure around $120 \mu \mathrm{s}$. These data agree with the times calculated according to the position of the pressure gauges and the wave speed in water $c_{\mathrm{w}}$. As shown in these curves, the pressure time history changes as a function of the location of the pressure gauge as well as the velocity of the projectile. The pressure level is highly sensitive to the projectile velocity, the peak pressure at $900 \mathrm{~m} / \mathrm{s}$
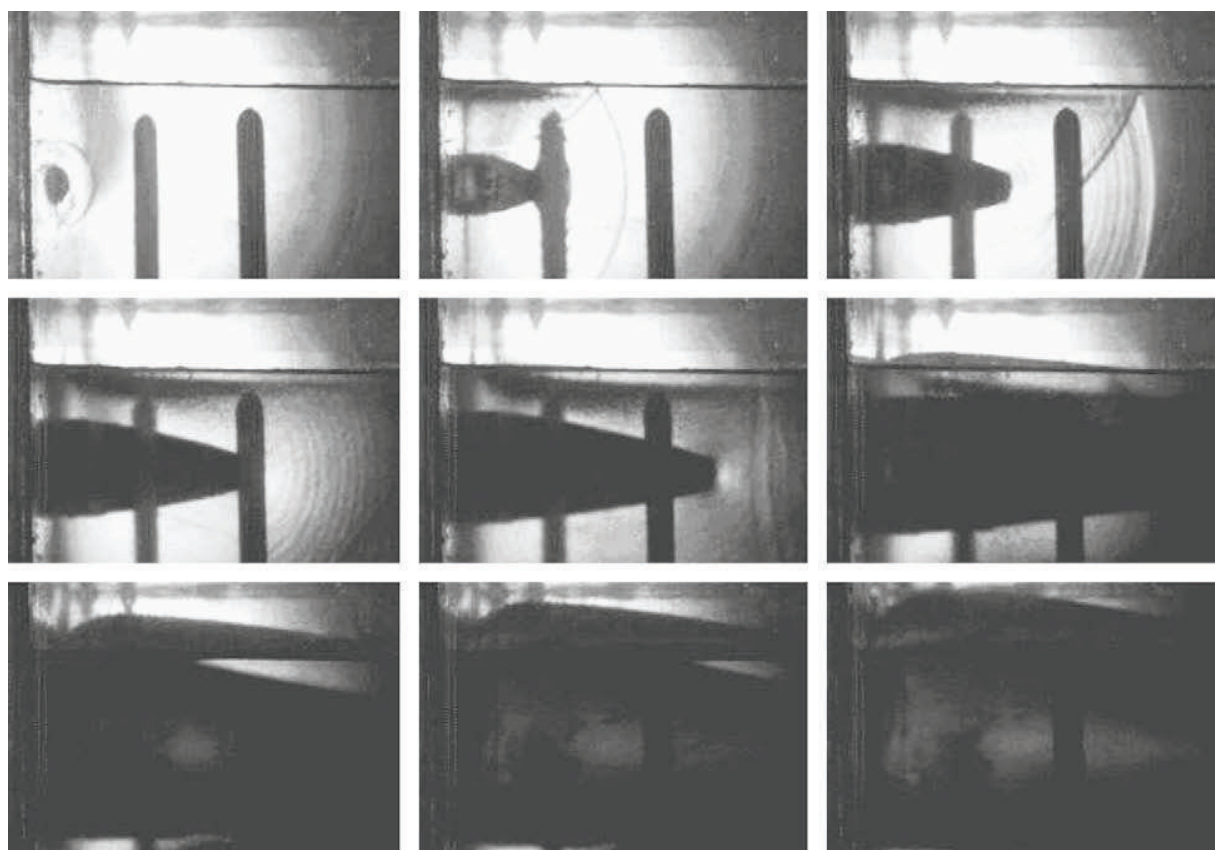

Fig. 8. Sequence of projectile penetration into tube filled $75 \% . V \quad 900 \mathrm{~m} / \mathrm{s}$; images taken at $4 \mu \mathrm{s}, 31.7 \mu \mathrm{s}, 59.4 \mu \mathrm{s}, 87.1 \mu \mathrm{s}, 114.8 \mu \mathrm{s}, 170.2 \mu \mathrm{s}, 281 \mu \mathrm{s}, 336.4 \mu \mathrm{s}$, and $391.8 \mu \mathrm{s} ; t \quad 0$ corresponds to initial contact. 

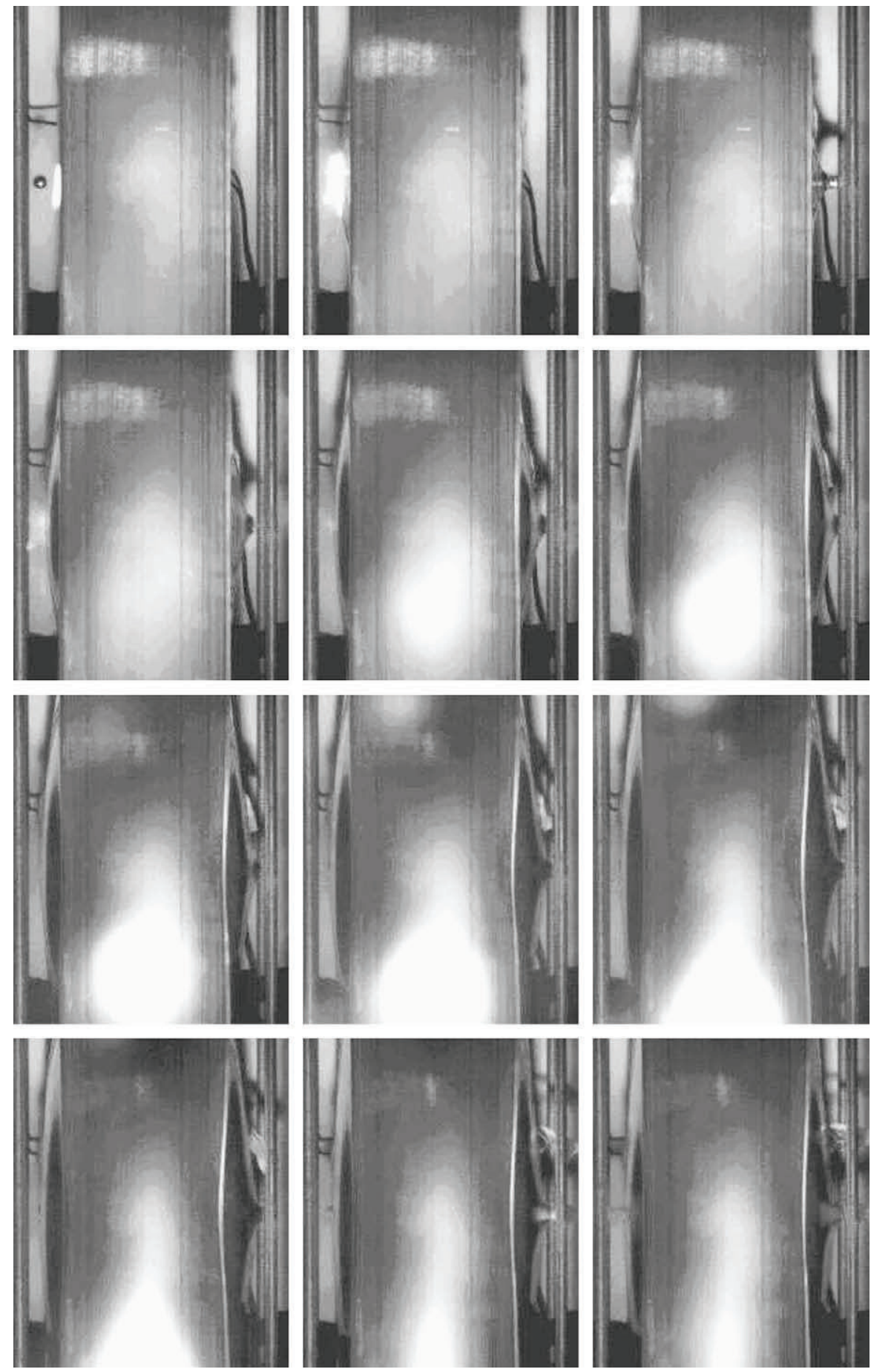

Fig. 9. Deformation process of tube filled $100 \% . V \quad 900 \mathrm{~m} / \mathrm{s}$; images taken at $-21.3 \mu \mathrm{s}, 178.5 \mu \mathrm{s}, 245.1 \mu \mathrm{s}, 345 \mu \mathrm{s}, 444.9 \mu \mathrm{s}, 544.8 \mu \mathrm{s}, 678 \mu \mathrm{s}, 811.12 \mu \mathrm{s}, 1.011 \mathrm{~ms}, 1.211 \mathrm{~ms}, 1.777 \mathrm{~ms}$, and $2.310 \mathrm{~ms} ; t \quad 0$ corresponds to initial contact.

being nearly double that reached at $600 \mathrm{~m} / \mathrm{s}$. Consequently, velocity will strongly affect the level of permanent deformation of the tube. Since the energy of the spherical pressure wave decreases with the distance from the source, the position of the sensor also influences the pressure recorded by it. Fig. 12 shows the area $A_{\mathrm{p}}$ below the pressure time curve (in the time interval $[0,0.5] \mathrm{ms}$ ), as a function of volume percentage for the different velocities considered. This parameter was also used by Wierzbicki and Moussa [33] to char acterize the transverse loading in an aircraft fuel tank under HRAM, uncoupling the fluid structure interaction problem. The influence of impact velocity and position of the pressure sensor is also no ticeable in the curves.

Regarding the filling percentage, the main difference observed is the duration of the pressure pulse, which decreases as the fluid level falls (Fig. 11). This is due to the effect of the rarefaction wave formed at the free surface. The pressure wave reaches the sensor at a time

$t_{0} \quad \frac{L}{c_{\mathrm{W}}}$ 
a

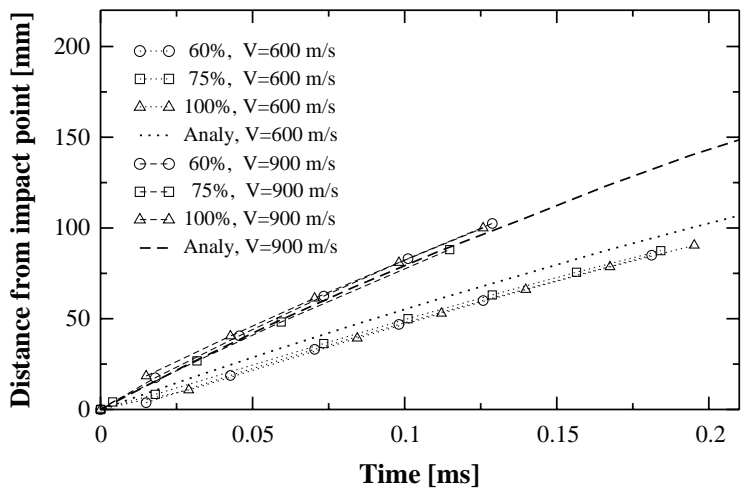

b

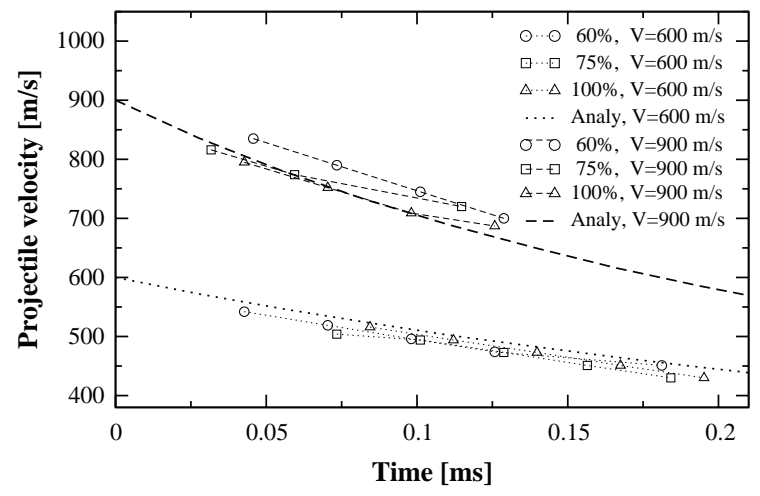

Fig. 10. (a) Comparison of position of the projectile vs. time. (b) Comparison of velocity decay vs. time.

$L$ being the distance between the sensor and the impact point. The rarefaction wave reaches the sensor at a time

$t_{1} \quad \frac{\sqrt{ } L^{2}+4 d^{2}}{c_{\mathrm{W}}}$

$d$ being the depth at which the sensor is placed (Fig. 13). Thus, the pressure pulse lasts for a period

$T(L) \quad t_{1} \quad t_{0} \quad \frac{\sqrt{ } L^{2}+4 d^{2} \quad L}{C_{\mathrm{W}}}$

which increases with $d$, that is, with the filling level. This effect is more relevant at locations closer to the impact point. As one moves away from this point, the radius of the rarefaction wave increases, being comparable to that of the pressure wave, and both fronts travel close to each other (Fig. 13). The area $A_{\mathrm{p}}$ under the pressure time curve recorded at a distance $L$ from the impact point may be written as

$A_{\mathrm{p}}(L) \quad \bar{P}(L) T(L) \quad \bar{P}(L) \frac{\sqrt{ } L^{2}+4 d^{2} \quad L}{C_{\mathrm{W}}}$

$\bar{P}(L)$ being an average value of the pressure at $L$. Assuming a varia tion of $\bar{P}$ inverse to the square of the distance $L$

$\bar{P}(L) \approx \bar{P}_{L} \quad L_{0}\left(\frac{L_{0}}{L}\right)^{2}$

$A_{\mathrm{p}}$ becomes

$A_{\mathrm{p}}(L) \approx \bar{P}_{L} \quad L_{0}\left(\frac{L_{0}}{L}\right)^{2} \frac{\sqrt{ } L^{2}+4 d^{2} \quad L}{C_{\mathrm{W}}}$

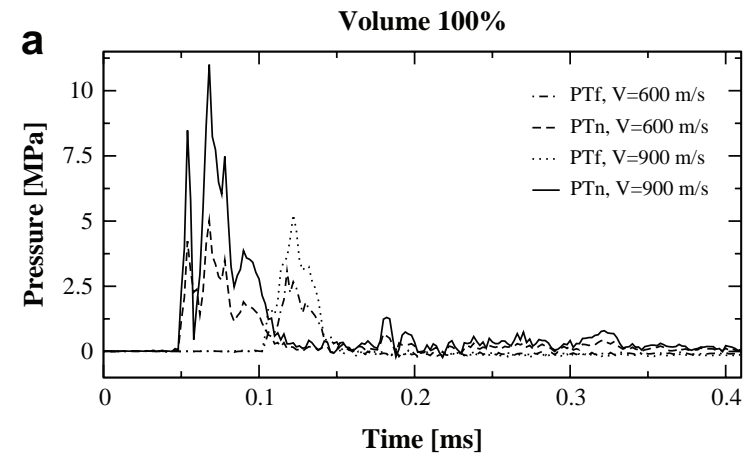

$L_{0}$ being a reference distance where the average pressure takes the value $\bar{P}_{L} L_{0}$. The sensitivity of $A_{\mathrm{p}}$ to the filling level may be calcu lated as

$\frac{\partial A_{\mathrm{p}}}{\partial d} \approx \bar{P}_{L} \quad L_{0}\left(\frac{L_{0}}{L}\right)^{2} \frac{4 d}{c_{\mathrm{w}} \sqrt{ } L^{2}+4 d^{2}}$

and the influence of $d$ on $A_{\mathrm{p}}$ decreases with the third power of $L$. Then the effect of the filling percentage is notable at the position of the pressure sensor PTn but not at PTf (Fig. 12).

\subsection{Deformation of the impacted specimens}

Fig. 14 shows the differences in permanent deformation be tween a completely filled tube and an empty one, both impacted at $900 \mathrm{~m} / \mathrm{s}$; the empty tube presents no bulge, while the filled tube presents pronounced bulging on the four sides. Without fluid, the aluminium tube presents two circular holes with no plastic deformation around them (Fig. 15a and c). The filled tube presents on the entry wall a perfectly circular hollow, while the exit one presents crack propagation and petalling since the exit wall is pre stressed before penetration due to the inner pressure (Fig. 15b and d).

Differences in the deformation of the cross section were also detected for tubes completely and partially filled (Fig. 16). When the tube was completely filled, all four sides bulged in a homoge neous way. Nevertheless, when the tube was partially filled, bulg ing occurred only up to the fluid level. The wall which was not in contact with the fluid underwent a very localized bulge in the longitudinal direction due to the impact of the fluid raised by the projectile movement.

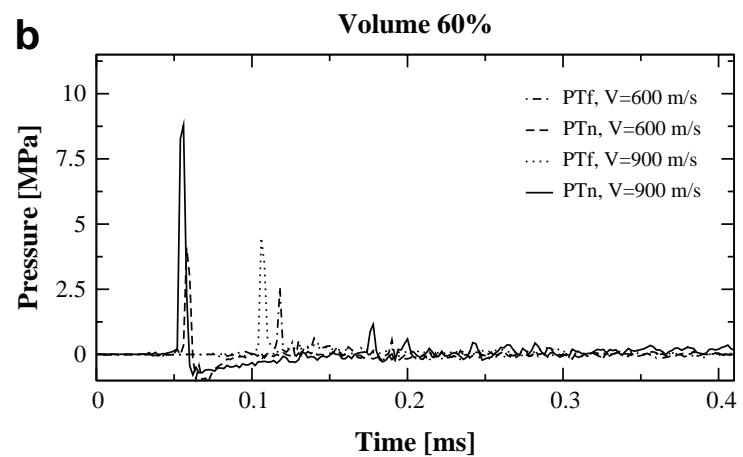

Fig. 11. (a) Pressure time history in a tube $100 \%$ filled impacted at 900 and $600 \mathrm{~m} / \mathrm{s}$. (b) Pressure time history in a tube $60 \%$ filled impacted at 900 and $600 \mathrm{~m} / \mathrm{s}$. 


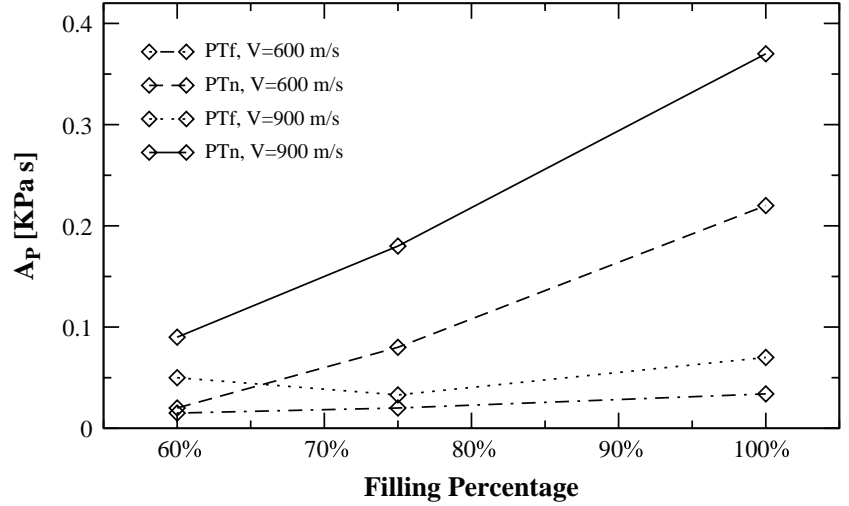

Fig. 12. Area under pressure signals vs. volume percentage.

\subsection{Strain time history}

After the passage of the pressure and rarefaction waves, the cavity started to grow due to the advance of the projectile moving the fluid away from its path. This increase in the inner volume forced the tube to deform. The rate of growth of the cavity depended largely on the impact velocity, as reflected by compari son of Figs. 6 and 8, and the acceleration of the fluid particles to wards the walls of the tube increased with the velocity of the projectile. The kinetic energy of the fluid was transferred to the walls which deformed plastically. The impact velocity may then influence the level of permanent deformation of the tube. On the other hand, an incomplete filling of the tube permits the fluid to expand through the unfilled volume. Therefore, a lower filling percentage will lead to a smaller permanent deformation of the tube. This was confirmed by the strain time history recorded during the test at different points of the tube.
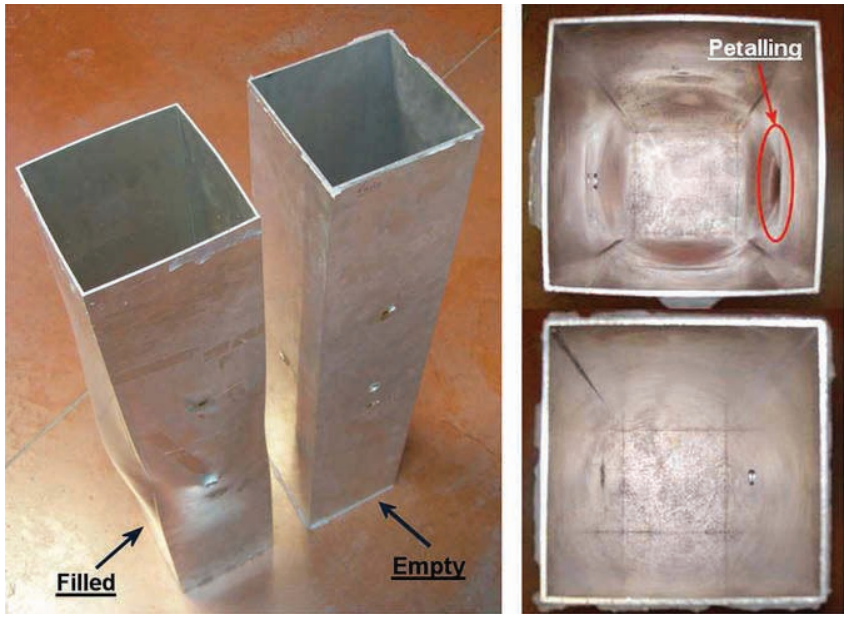

Fig. 14. (a) Comparison between a tube completely filled and an empty one impacted at $900 \mathrm{~m} / \mathrm{s}$. (b) Inside view of previous tubes.

As mentioned above, two strain gauges were located in the im pact wall (Fig. 4), G1 and G2. The exit wall was instrumented with other two strain gauges, G3 and G4 placed at the same positions as G1 and G2, respectively. Another strain gauge, G5 registered strain at the middle of the specimen lower wall (Fig. 4). Fig. 17 depicts strain data at G1, the gauge closest to the impact point, for different tests performed. It was found that the strain was firstly influenced by the velocity, and then by the filling percentage. The same behaviour was repeated at $\mathrm{G} 3$, placed in the exit wall. The maximum strain values found at G3 were almost the same as at G1, and they correspond to a time of approximately $1.5 \mathrm{~ms}$, which is in agreement with the time of maximum deformation observed in the video.

Fig. 18 shows data at G2 for the different tests performed. Contrary to the cases where the gauges were close to the impact

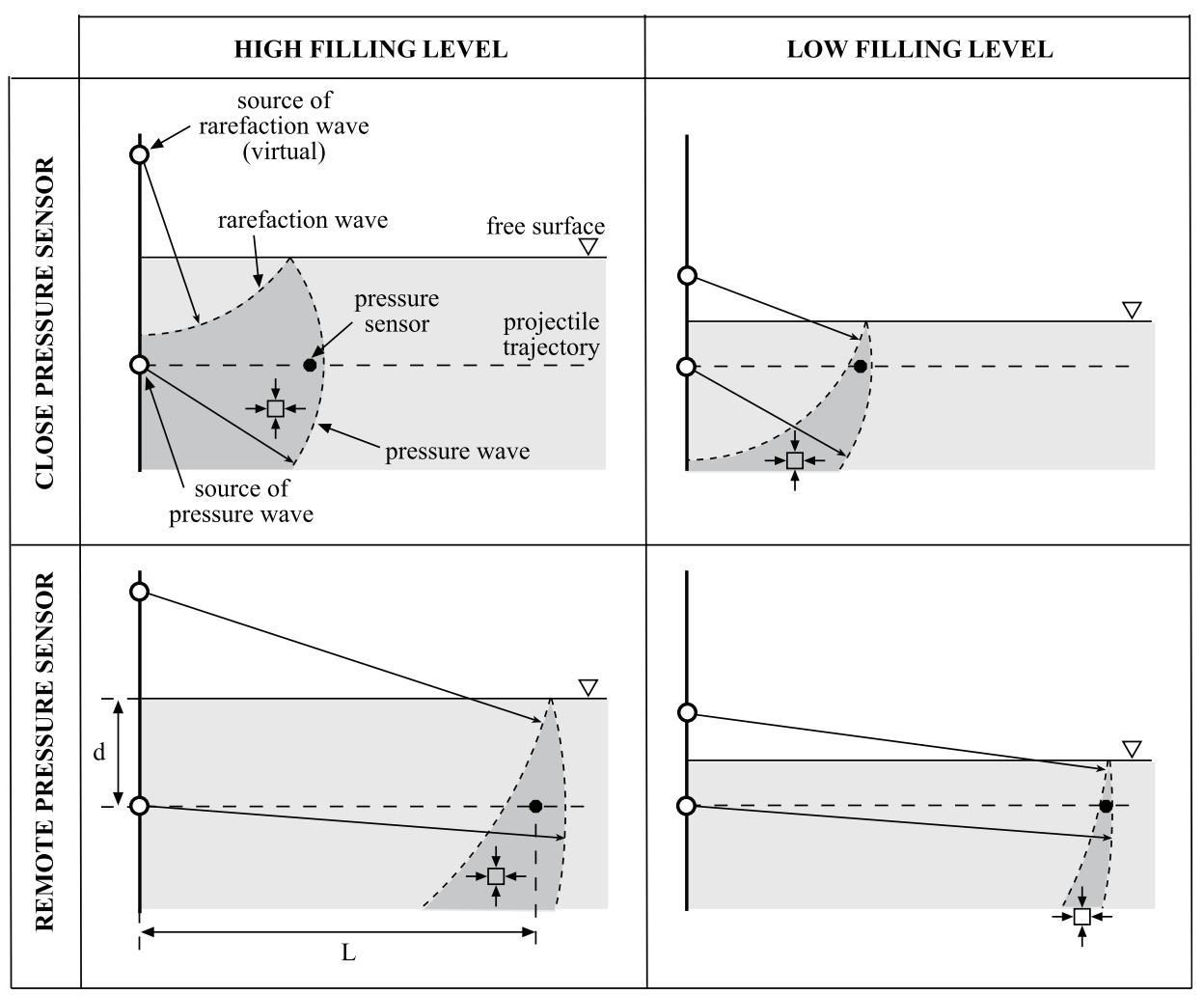

Fig. 13. Sketch of waves propagation for different filling levels. 

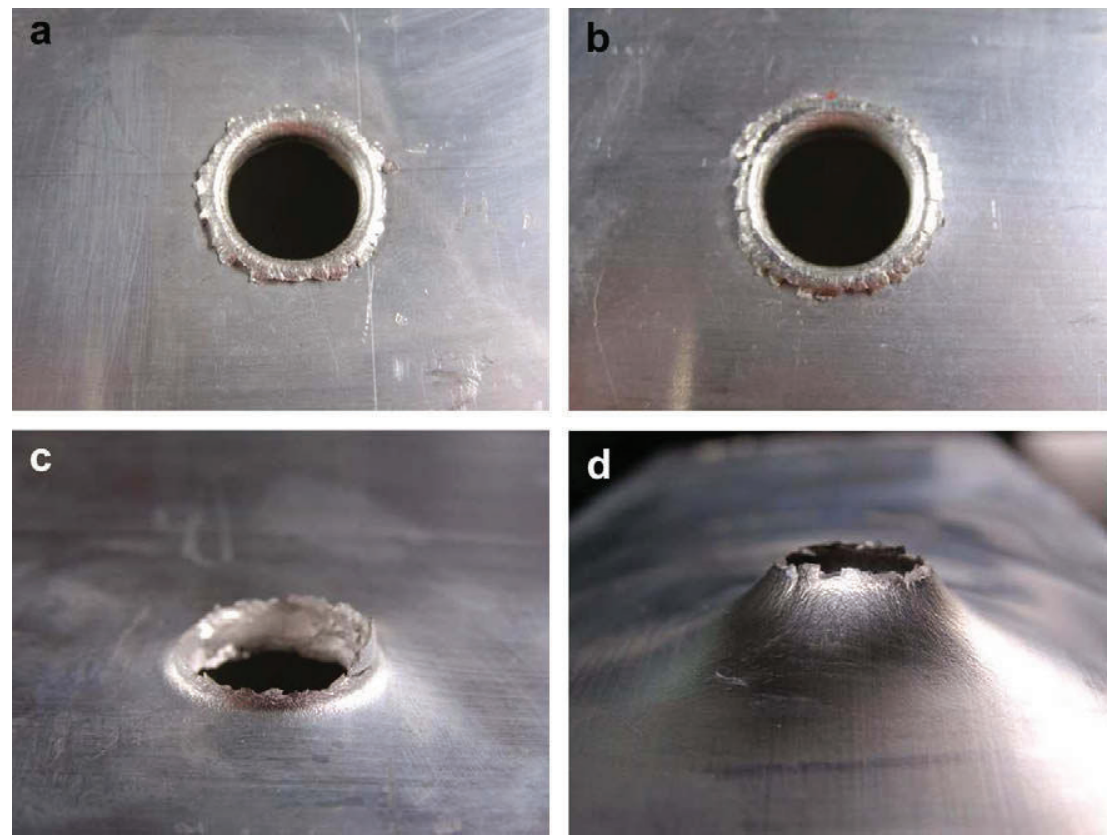

Fig. 15. Tube hollows caused by the projectile impact: (a) entry wall, empty tube; (b) entry wall, filled tube; (c) exit wall, empty tube; and (d) exit wall, filled tube.

point, the strain was firstly influenced by the filling percentage, and then by the velocity. The results at G4 (at the same position as G2 but in the exit wall) reflected the same behaviour, the maximum strains being very similar to the values found at G2.

Strain time history in the middle of the lower wall and directly below the trajectory of the projectile (G5) is shown in Fig. 19. The

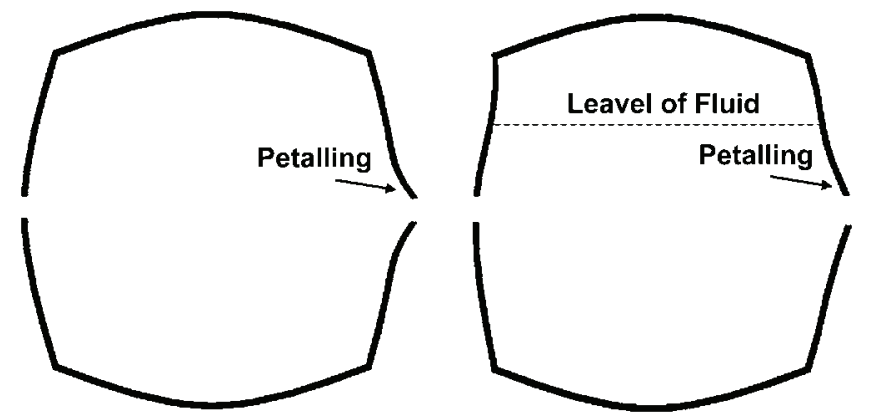

Fig. 16. (a) Profile of fully filled tube after impact. (b) Profile of partially filled tube after impact.

G1

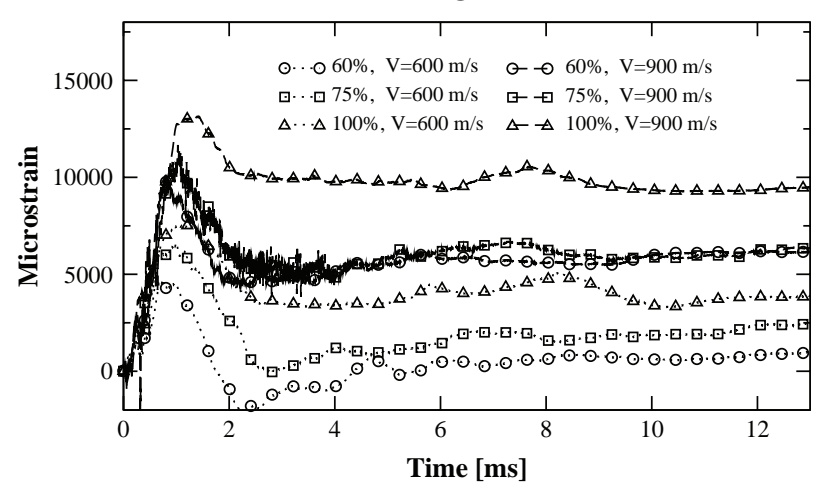

Fig. 17. Strain-time history in G1 for different cases. strain values were influenced firstly by the velocity and then by the volume, as in the case of G1 and G3.

According to these results, strains far from the impact area are more influenced by the filling percentage than by the velocity. That

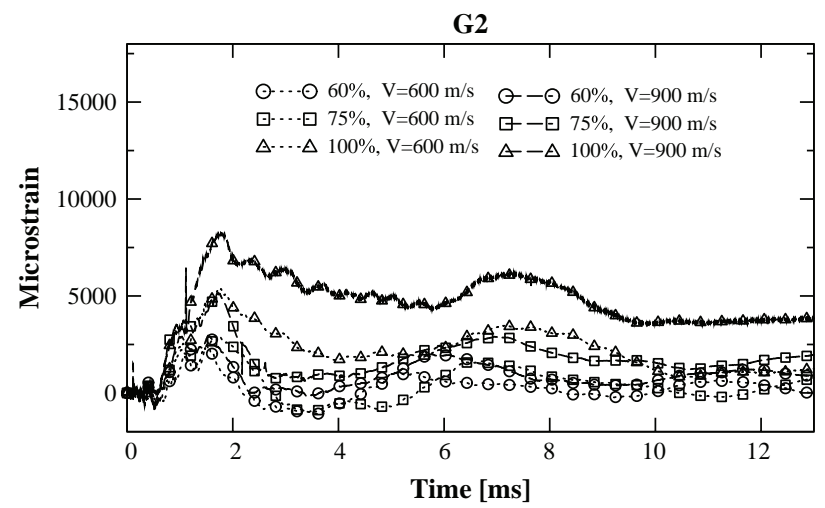

Fig. 18. Strain-time history in G2 for different cases.

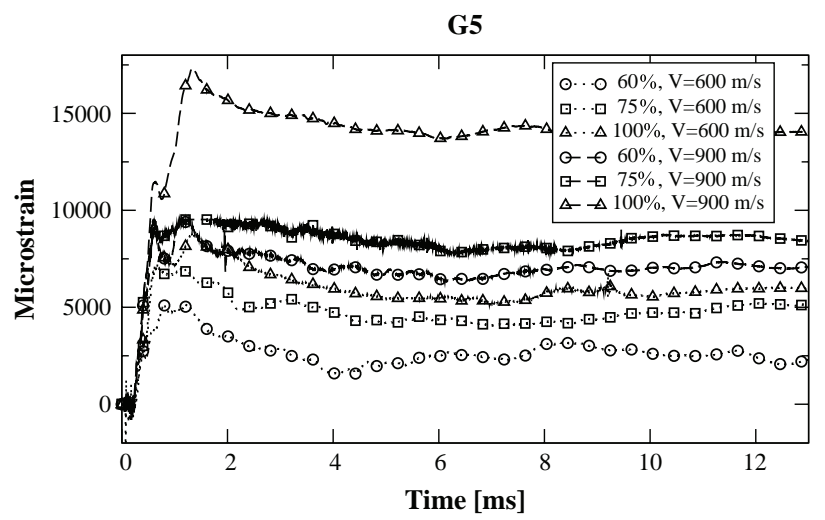

Fig. 19. Strain-time history in G5 for different cases. 

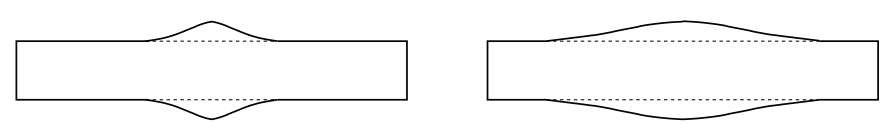

Fig. 20. (a) Zone affected by the variation of the impact velocity. (b) Zone affected by the variation of the filled percentage.

is, higher strains were found for a completely filled tank than in another partially filled one, although the latter was impacted at a higher velocity than the former. That trend changed at points close to the trajectory of the projectile. Strains in those points are firstly influenced by the velocity and then by the filling percentage.

Fig. 20 shows the effects of impact velocity and filling percent age in a schematic way. The effect of the velocity on the tubes is to generate a localized bulge, while the filling level produces a distri bution of the deformation on the tubes.

\section{Conclusions}

Water filled aluminium square tubes filled with fluid at differ ent levels were experimentally impacted by spherical steel pro jectiles at different velocities. A complete instrumentation of the specimens with pressure sensors and strain gauges, as well as the recording of the penetration process of the projectile into the fluid, allowed a complete analysis of the HRAM phenomenon, leading to the following conclusions:

The presence of fluid inside the aluminium tube has a notice able effect on its deformation, after undergoing the impact of a high velocity projectile. The plastic deformation reaches a large area, since the projectile transmits its kinetic energy to the walls of the tube through the fluid.

The high speed photographs of the impact depicted the dif ferent phases of the HRAM process. During the shock phase, a high intensity pressure wave reaches the walls of the tube and the free surfaces of the fluid (when partially filled); the deformation of the tube begins at this phase. During the drag and cavitation phase, much longer than the previous one, the fluid accelerates towards the surrounding walls and the tube undergoes large inelastic deformation.

The intensity of the pressure pulse during the shock phase depends on the impact velocity and on the measurement point. The influence of the filling level is important at points close to the impact zone, but not at remote locations.

The momentum normal to the walls transmitted from the projectile to the fluid during the drag and cavitation phase is the most important factor influencing the deformation of the tube. At high impact velocities, this momentum is greater due to the higher rate of growth of the cavity. At incomplete filling, the fluid moves towards the walls only in the region close to the projectile trajectory. At larger dis tances, the fluid expands parallel to the walls through the unfilled volume. Therefore, high velocity impacts and low filling levels cause a localization of the permanent de formation in the tube at regions close to the projectile trajectory.

\section{Acknowledgements}

This research was done with the financial support of the Spanish Ministry of Education under Project reference DPI2005 06769, and of the University Carlos III of Madrid and Comunidad Autónoma de Madrid under project reference CCG07 UC3M/DPI 3395. We wish to express sincere gratitude to Mr. S. Puerta for his valuable help during experimental testing.

\section{References}

[1] Addessio FL, Schraad MW, Lewis MW. Physics-based damage predictions for simulating testing and evaluation experiments. LA-UR-97-4877. Los Alamos National Laboratory; 1997.

[2] Stephani P, Middendorf P, Less Ch, Numerical analysis of the hydrodynamic ram of a CFRP integral tank. In: International conference on structures under shock and impact IX, New Forest, England, vol. 87; 2006. p. 45-53.

[3] Santini P, Palmieri D, Marchetti M. Numerical simulation of fluid-structure interaction in aircraft fuel tanks subjected to hydrodynamic ram penetration. In: 21st ICAS congress, Melbourne, Australia; 1998 [Paper ICAS-98-4.3.2].

[4] Lundstrom EA, Stull E. Fluid dynamic analysis of hydraulic ram II (results of experiments). JTCG/AS 73-T-291, Joint Technical Coordinating Group/Aircraft Survivability.

[5] Lundstrom EA. Fluid dynamic analysis of hydraulic ram. NWC TP 5227. Naval Weapons Center; 1971

[6] Lundstrom EA, Fung WK. Fluid dynamic analysis of hydraulic ram IV (user's manual for pressure wave generation model). JTCG/AS 74-T-018. Joint Technical Coordinating Group/Aircraft Survivability; 1974.

[7] Ball RE. Structural response of fluid-containing-tanks to penetrating projectiles (hydraulic Ram). A comparison of experimental and analytical results. NPS-57B p76051. Monterrey, California: Naval Post Graduate School; 1976.

[8] Bates Jr KS. Aircraft fuel tank entry wall-projectile interaction studies. Master's thesis, NPS; 1973.

[9] Holm DP. Hydraulic ram shock wave and cavitation effects on aircraft fuel cell survivability. Master's thesis, NPS; 1973.

[10] Soper WR. Hydraulic ram studies. Master's thesis, NPS; 1973.

[11] Fuhs AE, Ball RE, Power HL. Fy 73 hydraulic ram studies. NPS-57Fu74021; 1974

[12] Mueller LS. Experiments in hydraulic ram. Master's thesis, NPS; 1974.

[13] Kappel LC. Hydraulic ram shock phase effects on fuel cell survivability. Master's thesis, NPS; 1974.

[14] Power HL. Fy 74 experimental hydraulic ram studies. NPS-57Ph74081; 1974.

[15] Holm CM. Hydraulic ram pressure measurements. Master's thesis, NPS; 1974

[16] Page B. Entry wall strain measurements during hydraulic ram. Master's thesis, NPS; 1975.

[17] Patterson JW. Fuel cell pressure loading during hydraulic ram. Master's thesis, NPS; 1975.

[18] Power HL. Fy 75 experimental hydraulic ram studies. NPS-57Ph75061; 1975.

[19] Fahrenkrog SL. A study of the crack damage in fuel-filled tank walls due to ballistic penetrators. Master's thesis, NPS; 1976.

[20] Bless SJ, Barber JP, Fry PF, Newman RK. Studies of hydrodynamic ram induced by high velocity spherical fragment simulators. Technical report, AFML-TR-77$11 ; 1977$.

[21] Bless SJ. Fuel tank survivability for hydrodynamic ram induced by high-velocity fragments. Part I. Experimental results and design summary. Technical report, AFFDL-TR-78-182, Part I; 1979.

[22] Copland A. Hydrodynamic ram attenuation. ARBRL-MR-03246. US Army Ballistic Research Laboratory; 1983.

[23] Avery JG, AGARD. Design manual for impact damage tolerant aircraft structure. London, UK: Technical Editing and Reproduction Ltd.; 1981.

[24] Lundstrom EA, Anderson T. Hydraulic ram model for high explosive ammunition. In: Symposium on shock and wave propagation, fluid-structure interaction and structural responses. ASME pressure vessels and piping conference, Honolulu; 1989.

[25] Sparks CE, Hinrichsen RL, Friedmann D. Comparison and validation of smooth particle hydrodynamic (SPH) and coupled Euler Lagrange (CEL) techniques for modeling hydrodynamic ram. In: 46th AIAA/ASME/ASCE/AHS/ASC structures, structural dynamics \& materials conference, Austin, Texas; 18-21 April 2005 [AIAA 2005-2331].

[26] Seddon CM, Moodie K, Thyer AM, Moatamedi M. Preliminary analysis of fuel tank impact. International Journal of Crash 2004;9(3):237-44.

[27] Poehlmann-Martins F, Gabrys J, Souli M. Hydrodynamic ram analysis of nonexploding projectile impacting water. In: 2005 ASME pressure vessels and piping division conference, Denver, Colorado; 17-21 July 2005 [PVP 200571658].

[28] Nishida M, Tanaka K. Experimental study of perforation and cracking of waterfilled aluminum tubes impacted by steel spheres. International Journal of Impact Engineering 2006;32:2000-16.

[29] Anghileri M, Castelleti LML, Tirelli M. Fluid-structure interaction of water filled tanks during the impact with the ground. International Journal of Impact Engineering 2005;31(3):235-54.

[30] Xie WF, Liu TG, Khoo BC. The simulation of cavitating flows induced by underwater shock and free surface interaction. Applied Numerical Mathematics 2007;57(5-7):734-45.

[31] Kedrinskii VK. Rarefaction waves and bubbly cavitation in real liquid. In: Proceedings, Fourth International Symposium on Cavitation, Pasadena (CA) USA; 2001 [CAV 2001]: session B4.001.

[32] Gerhart PM, Gross RJ, Hochstein JI. Fundamentals of fluid mechanics, Reading, Massachusetts, E.U.A: Addison-Wesley Publishing Co.; 1992 [Chapter 8].

[33] Wierzbicki T, Moussa NA. Deformation and rupture of an aircraft fuel tank under hydraulic RAM pressure loading. In: Proceedings of the 63rd shock and vibration symposium, Las Cruces, New Mexico, vol. 2; 1992. p. 771-79. 